\title{
Interactive Theoretical Model of Text Processing Reflected in Reading Comprehension: An Experimental Study
}

\author{
Azadeh Elmianvari \\ Department of Linguistics, Gent University, Gent, Belgium \\ Reza Kheirabadi \\ Organization for Educational Research and Planning (OERP), Tehran, Iran
}

\begin{abstract}
Basing on the interactive model of comprehension and learning, this study investigated the teaching of text structure among EFL Iranian students and its effects on their reading comprehension. It was designed with the assumption that readers who already have the knowledge of the organizational patterns of text will be aware of text structure and will use it as a strategy to comprehension. Therefore the use of text structure, or the structure strategy, will enhance their comprehension and learning from text. Fifty six students of intermediate level, divided into two groups of control and experimental, participated in this study. Students attempted a pre and a post reading comprehension tests before and after the training procedure which involved an extra treatment on rhetorical structures for the experimental group. The performance of these two groups was compared using t-test. Study results revealed that experimental students who employed text structure had significantly higher performance on the multiple choice reading comprehension questions than those who did not receive any training on text structure. This indicates that the knowledge of text structure may have facilitated their comprehension and learning from text. Therefore, the explicit teaching of expository text structure knowledge and the effective use of structure strategy could be inserted in the instructional program of second/foreign language learners.
\end{abstract}

Index Terms-expository texts, formal schema, interactive model, schema theory, structure strategy, text structure

\section{INTRODUCTION}

"Education is carried out, primarily, through the reading and study of prose text". (Dewalt, Rhyne-Winkler, \& Rubel, 1993, p. 93). This statement emphasizes the main goal of reading: reading texts in order to learning from them. Although students learn from texts, they are unable to learn everything printed on the page because of limited memory capacity. Instead, they have to extract main ideas and ignore less important details (Brown \& Smiley, 1978). Therefore it seems that they need to use specific reading strategies to comprehend the text effectively.

Since the information printed on the page is not sufficient for comprehension, the knowledge of the world involving background knowledge of the organizational structures of the reading text plays an essential role in text comprehension. Using text structure, or following the rhetorical organization of text while reading, has been recommended as an important strategy to enhance reading comprehension (Spearritt, 1982). As Carrel (1992) mentioned, the schema theoretic view of reading comprehension is associated with the interactive model: a text does not simply carry meaning in itself; instead, it provides directions for the learner to construct meaning from his/her previously acquired knowledge. This statement has been supported by a large number of researches. These researches emphasized the effects of text structure on the ability of first language readers to reconstruct meaning from texts (Meyer, 1982; Meyer, Brandt \& Bluth, 1980; Meyer \& Freedle, 1984).

On the other hand, fewer researches have been done to examine the effects of the teaching of text structure on second/foreign language reading comprehension. Regarding the limited number of researches in the area of foreign language reading, it seems reasonable to see if second/foreign language readers can also learn knowledge of how text is organized and use it in the comprehension of textual material. Then it is interesting to ask whether or not the knowledge of text structure enhances their comprehension and learning from texts.

Therefore, the present study was designed specifically to investigate the effect of teaching expository text structure on reading comprehension of Iranian EFL students, as measured by their performance on multiple choice reading comprehension questions. It is hoped that the results will clarify not only the role of text structure in English as a Second or Foreign Language reading comprehension, but also the pedagogical implications of teaching reading to ESL/EFL learners, particularly Iranian students.

Specifically, this study will investigate the effect of teaching expository text structure on reading comprehension of Iranian EFL students, as measured by three reading comprehension tests, each specifies with a special kind of rhetorical 
structure. The result may confirm the effective role of text structure knowledge in text comprehension. It is hope that the findings of this study may support the positive role of organizational pattern knowledge in reading ability of ESL/EFL students. To improve reading comprehension of foreign language learners, it seems that language teachers, testers and material developers might need to consider the impact of knowledge of expository text structure in preparing appropriate materials and techniques.

Reading specialists have recognized that identifying the structural organization used by the writer is an effective reading strategy. Readers who are aware of such patterns may better understand what they read. Based on schema theory this study tries to show that the structure of a text and how a reader recognizes that structure affect the amount of information the student remembers. It seems that passages are easier to remember when they have a clear organizational structure with related components. When students have learned what is meant by text structure, they may be ready to learn how to recognize the five common expository structures found in many content materials. So it seems that the knowledge of text organization affects comprehension especially in terms of the identification and recall of the most important information in a text.

Taylor and Samuels (1983) found that a significant percentage of students are unaware of text structure; they do not use structure to understand and remember information from the structured texts. Students who lack specific knowledge about text structure and strategies for using it cannot be as successful in comprehension as those who received instruction on text structure.

Since being able to understand and remember information in texts is important for the English learners as they progress through the grades, it is hope that this research clarifies the important role of text structure knowledge in effective reading. To acquire this knowledge, students need strong teacher involvement. English teachers who are themselves knowledgeable about structure in general and about five common expository text structures in particular will provide their students with a starting point in dealing with content materials successfully.

Well-structured text may enhances recall and comprehension for those who have acquired the knowledge of structure and many studies have shown that instruction designed to teach students to recognize the underlying structure of text improves comprehension. The goal of this instruction is for the reader to internalize the strategy so that its use becomes automatic. Then, in situations in which comprehension is a problem, the strategy can be applied. It involves acquiring knowledge about text and using this knowledge strategically. Regarding the students' difficulties with reading comprehension in general and with text structure in particular, It might be expected that there will be great efforts to provide suitable instruction.

Results from the study might suggest effective reading strategies for Iranian students on the one hand, and guidance for improvement of reading instruction for the teachers, on the other hand. Additionally, the study would contribute to research on the effects of formal schemata on reading comprehension in English as a second/ foreign language.

A large number of first language reading research has revealed that teaching of textual organization affects readers' comprehension of text. For instance, good first language readers are able to use text structure better and write better by using the same rhetorical pattern as that of the author of the text and also they can recall the gist of the text better than do poor readers (Meyer, Brandt, \& Bluth, 1980; Richgels, McGee, Lomax \& Sheard, 1987). However, little comparable research has been done in second/foreign language reading. Because L1 reading is different from L2 reading, results from L1 reading research may not always be true in L2 contexts (Slater, 1985; Grabe, 1991); therefore, research on readers in second/foreign language contexts is necessary. Among the four language skills, reading seems to be the most important one because students need to use it to acquire the knowledge of English texts. Although Iranian students have learned English as a an essential subject since grade 7 in the school, teachers of English as a foreign language usually encounter with students whom fail to comprehend the English expository texts; however, they have adequate linguistic knowledge of English. In most English reading classes, great emphasis has been placed on teaching the knowledge of vocabulary and grammatical structures, while knowledge of text organization has not received any attention. Then, it is questionable if their difficulty in comprehension can be attributed to the fact that they do not have adequate strategies or skills (Carrell, 1988b), one of which is the structure strategy, to help them read and learn from text. Therefore, the present study has been designed to investigate the impact of teaching expository text structure on the reading comprehension of Iranian EFL students.

\section{REVIEW OF LITERATURE}

The schema theoretic view which is related to interactive model of text processing, claims that any given text does not simply carry meaning in itself. Instead, it provides directions for the learner to construct meaning from his/her previously acquired knowledge (Lee, 1986). At first Kant introduced the idea of back ground knowledge in a way that new information is related to what one already knows. According to interactive model and schema theory in reading, comprehension is the result of matching the existing schema with the new information printed on the page. Therefore in order to interpret a text meaningfully, a reader has to use his/her background knowledge effectively. In other words, it is the interaction between the reader and the text that is the foundation of comprehension (Talbot, 2004). Schema theory can be used in the interactive model of reading which mentions that the background knowledge readers bring to their reading is as important as the information in the text. Text by itself does not carry meaning instead; readers construct meaning from their prior knowledge. Accordingly, research on the effects of schemata on reading comprehension of 
English readers has examined in several studies.

Hooshmand (1984) examined the role of schemata in comprehension. Students were presented a passage. Some of the students were told the structure and the content of the passage and others were not. Students who were told about the passage recalled more than students who did not hear that knowledge. The study has shown that when subjects are provided with a schema against which to understand and recall a passage, they perform better than when they are not given such a schema.

In another study, Anderson, Reynolds, Schallet, and Goetz (1977) have found that the reader's familiarity with the text affects reading comprehension. This study took two distinct passages with two different structures. The passages were given to subjects from the physical education department whom were taught different kinds of structures and to subjects from the music department. The results showed that subjects interpreted the texts according to their specialized background knowledge; besides, students of physical education over performed the other group.

In order to understand the role of schema or knowledge of text structure, it is important that the meaning of text structure is defined. The terms text structure, rhetorical structure, or discourse structure refer to the organization of text information (Aebersold \& Field, 1997). It can also refer to the organization of ideas in text (Taylor, 1982). It "specifies the logical connections among ideas and the subordination of some ideas to others". (Meyer, 1982, P.39). Moreover, schema theory or text structure guides the author during writing and helps the reader to identify the relationship among ideas in the text (Meyer, 1982; Meyer, Brandt \& Bluth, 1980). "Passages that are organized contribute to more efficient learning than those that are randomly organized or disorganized" (Meyer \& Freedle, 1984, P.142 cited in Meyer, 1982 ). According to Meyer (1982), passages can be classified into five basic types of expository prose. These five types are collection, description, causation, problem-solution, and comparison.

There are two opposing views on second language/foreign language reading: reading ability in a second or foreign language is the result of either the proficiency in that language or the reading ability in one's first language (Coady, 1979 cited in Carrell, 1988a). Regarding the latter view, researchers argue that some main skills may be transferred to a second language and may compensate for inadequacies in linguistic skills (Carrell, 1988a). Knowledge of organizational structure has been shown to affect what is comprehended and recalled from a text in L1. Compared to ESL/EFL reading, however, there seems to be lots of researches on the effects of the rhetorical structures of expository prose on comprehension by L1 readers.

Although less research has been done to examine the role of background knowledge of text structure in ESL/EFL reading comprehension, some research studies on ESL/EFL readers have also revealed its facilitative effects on comprehension. Meyer and Freedle's (1984) study investigated the effects of four discourse types of expository prosecomparison, causation, problem/solution, and collection of descriptions-on the recalls of native readers of English and found that the more organized discourse types of comparison, problem/solution, and causation facilitated comprehension and recall.

Carrell (1984a), replicated their study in which she investigated the effects of the four English organizational patterns on the recalls of advanced ESL readers from different language backgrounds. Subjects were 80 students who read the texts each with a specific type of formal schema. After that they took a reading test and a delayed reading test. The study results indicated that if ESL readers possessed the appropriate formal schema for processing the text, more information was comprehended. In addition, similar to the findings in Meyer and Freedle (1984), the findings in this study also revealed that different types of rhetorical organizations had different effects on the recalls of ESL readers. The recall of more tightly organized discourse types was significantly better than that of the loosely organized type. Therefore, "devoting reading instruction to the identification of different discourse structures may be effective in facilitating ESL reading comprehension, retention, and recall" (p. 138).

In another study, Carrell (1992) investigated the students' recall of texts which were written in different text structures. Subjects, who were 45 ESL students at high-intermediate proficiency level, read two passages, one written in a comparison/ contrast text structure, and the other, in a collection of description. After reading each passage, they did a test to recall the information they read. Study results revealed that subjects who used the text structure of the passage to organize their mind recalled more main ideas and major topics of the reading passage.

Many students do not develop reading comprehension skills without the explicit teaching of comprehension strategies. Research shows, that the explicit teaching of comprehension is uncommon. Kendeou \& Broek (2007), reported a scarcity of comprehension instruction. As Kendeou \& Broek pointed out, "we were struck by the almost complete absence of direct instruction about comprehension strategies" (p. 157). Then, many students experience problems in comprehension of written text, especially the more complex expository text. There are many reasons for this, for example they can't see the basic structure of text. Some students get lost in the words and can't see the big picture (Dymock, 2005). Some students require direct instruction in comprehending more complex expository text structures. (Kendeou \& Broek, 2007)

Newman (2007), investigated the effect of explicit instruction of expository text structure on reading comprehension. The subjects were third grade EFL students and they were divided into three groups of experimental and a control group The experimental groups received training on text structure with the use of graphic organizer. The students in the control classroom received regular Guided Reading instruction. The trainer used different reading strategies such as modeling, thinking aloud, and graphic organizers during the treatment of experimental groups. After the post test 
subjects of control and experimental groups showed a significant difference in their ability to comprehend expository text.

Piyanukool (2001), investigated the effectiveness of teaching reading through discussion of text structures on students' reading comprehension. The subjects in the study were $126 \mathrm{EFL}$ students who were divided into two control and experimental groups randomly. Students in experimental group received training on using and applying text structure knowledge on the stories. In the training procedure both narrative and expository text structures were used. The control group was asked to answer the questions at the end of stories. After the post test a t-test was used. The results did not reveal any differences between two groups' performance but it was found that the participants liked reading through discussion of text structures more than reading by themselves.

In summary, the earlier studies reviewed here have shown that the training of text structure enhances learners' comprehension, learning, and recall of text. This could be a support to the fact that the knowledge of expository text structure is a valuable strategy which facilitates the reader's reading comprehension and learning from text.

\section{METHODOLOGY}

To answer the research question: "Does explicit teaching of different kinds of expository text structure affect EFL students' reading comprehension?", this chapter concentrates on the practical side of the present study. Sufficient details about the subjects participating in the study, the instrumentation, the way they were administered and the procedure will be discussed. In addition, the statistical analysis required for conducting this experiment will be presented.

The participants of this experimental research were fifty nine female Iranian learners of English as a foreign language. Their English proficiency could be classified at intermediate level and their age ranged from seventeen to twenty six years old. Students made up a homogeneous group whose similar English proficiency level was approved through an original PET test (preliminary English Test). Since two students did not take the post- test, their data were eliminated from the study. In addition, one subject's score did not fit the homogeneous pattern of the research and was not considered part of the study, though she received the same treatment. The remaining participants, fifty six EFL learners, were divided into control (28 students) and experimental (28 students) groups. The study was carried out during the students' regular English classes in Farzaneh English Institute, where the researcher conducted the study during the summer 2008.

The first instrument used to measure the testee's language proficiency level, was the reading comprehension section of an English proficiency test -PET test- including 35 multiple choice questions. This instrument was used in the research to minimize the individual differences among the participants. It served as a criterion for validating the teacher- made reading comprehension test used in the study as well. It was the original standard test form 100/2031/7 that was distributed to the examinees all over the world in 2004.

The reading comprehension sections in students' text book- third volume of Interchange Third Edition (2005), by Richards - involved different types of expository text structure. Accordingly the researcher taught all these patterns to see their effect on students' reading comprehension and since "description", "comparison-contrast" and "cause-effect" were the most frequent and tightly organized ones in students" text book, they were chosen as rhetorical structure of pre, post reading comprehension tests. At first, the teacher-made reading comprehension test including three passages and twelve questions was administered among a pilot group of thirty students; then, based on the results, the pre-post reading comprehension test supplemented with multiple choice questions was developed.

The main objective of this experimental research was to determine whether instruction focusing on text structure helps students to improve their comprehension of expository text. The procedure used in developing the instruments of the study, the administration of the tests as well as other considerations like reliability and validity of the instruments will be further elaborated in this section.

Regarding the procedure of selecting a sample, the convenience sample -"a sample which is chosen solely from available subjects" -including fifty nine female Iranian EFL learners, was chosen to be treated. (Richards \& Schmidt, 2002, p.465). Students were informed that their performance in the study would not affect their course grade.

The pilot test, an approval for the teacher-made questions, was conducted among thirty EFL intermediate students at Odaba English Institute where the pilot group answered twelve multiple choice teacher- made questions of reading comprehension. Since preparing appropriate passages was the researcher's main concern, three passages of different expository text structure types with respect to their difficulty level, length, content and readability index were chosen. Researchers argue that lack of control over these factors may account for the inconsistent findings. (Chung, 2000; Geva, 2004; Degand \& Sanders, 2002; cited in Abdolahzadeh, 2006). Based on the learners' text book, "description", "comparison-contrast" and "cause-effect" were the most frequently used rhetorical structures; so, they were selected as measures of text structure knowledge. The readability degrees of the reading passages of students' text book were calculated according to the Fog index formula. The average readability of students' text book was 25.11 . The readability degrees of the developed reading comprehension passages are demonstrated in table 3.1. According to the table the degrees were almost in the same range of the text book passages readability. 
TABLE 3.1

THE READABILITY OF DEVELOPED READING COMPREHENSION TEST

\begin{tabular}{|l|l|}
\hline Passages & Readability degrees \\
\hline $\begin{array}{l}\text { Passage 1 } \\
\text { (description) }\end{array}$ & 26.48 \\
\hline $\begin{array}{l}\text { Passage 2 } \\
\text { (comparison- contrast) }\end{array}$ & 22.90 \\
\hline $\begin{array}{l}\text { Passage 3 } \\
\text { (cause-effect) }\end{array}$ & 25.33 \\
\hline
\end{tabular}

After the teacher - made test administration, the reading comprehension part of an original English proficiency test Preliminary English Test - as a standard criterion, was likewise given to thirty subjects of the pilot group. To find out how effective the test items were and to find out if they indicated differences between high and low ability test takers, item difficulty and item discrimination were determined. If a particular question in a test is answered in totally different way by the test takers who do well on the test and by those who do poorly, the question is said to discriminate well between the students. (Richards \& Schmidt, 2002). Regarding the table 3.2, the questions number 1, 2, 3, 4, 7 and 10 could discriminate well. These items were well- prepared ones and since almost all test items showed high and positive item discrimination, none of them needed revision.

TABLE 3.2

\begin{tabular}{|c|c|c|c|c|c|c|c|c|c|c|c|c|}
\hline $\begin{array}{l}\text { Question } \\
\text { Number }\end{array}$ & 1 & 2 & 3 & 4 & 5 & 6 & 7 & 8 & 9 & 10 & 11 & 12 \\
\hline $\begin{array}{l}\text { Item } \\
\text { Discrimination }\end{array}$ & 0.45 & 0.45 & 0.45 & 0.45 & 0.40 & 0.25 & 0.45 & 0.40 & 0.40 & 0.45 & 0.40 & 0.40 \\
\hline
\end{tabular}

Item difficulty is a measure of the difficulty of a test item. The closer the item difficulty to 0.5 , the more favorable the test question. (Richards \& Schmidt, 2002). Therefore, almost all of the test items are said to be preferable.( table $3.3)$.

TABLE 3.3

ITEM DIFFICULTY INDEX

\begin{tabular}{|l|l|l|l|l|l|l|l|l|l|l|l|l|}
\hline $\begin{array}{l}\text { Question } \\
\text { Number }\end{array}$ & 1 & 2 & 3 & 4 & 5 & 6 & 7 & 8 & 9 & 10 & 11 & 12 \\
\hline $\begin{array}{l}\text { Item } \\
\text { Difficulty }\end{array}$ & 0.45 & 0.55 & 0.45 & 0.45 & 0.50 & 0.45 & 0.55 & 0.40 & 0.50 & 0.45 & 0.50 & 0.40 \\
\hline
\end{tabular}

To validate the developed test against the criterion (Preliminary English Test), the researcher used the test results to estimate the reliability and validity of the teacher-made test items. KR-21 formula was applied to estimate the test reliability. The results demonstrated a high degree of reliability (0.76) for the 12 item test which was administrated among 30 subjects. To investigate the concurrent validity of the test, the researcher conducted a correlation analysis between the language proficiency test and the developed comprehension test. The result of the variance analysis was also statistically high and preferable. $(\mathrm{r}=0.70)$.

This study is an attempt to investigate the effectiveness of teaching expository text structure to EFL learners in their reading comprehension. To achieve this end, the participants of the study were divided into two groups of control and experimental. The experimental group took advantage of receiving extra instruction: expository rhetorical structure awareness. The two groups' performance on a teacher-made reading comprehension tests were compared and the final result revealed whether the training was effective or not. The reading comprehension part of an original English proficiency test- as a standard criterion- was used by the researcher to homogenize the sample under the study. The criterion of sample homogeneity is that their scores set in one standard deviation below and above the mean. The administration of reading comprehension section of PET including thirty five multiple choice items on fifty nine EFL learners was carried out during 45 minutes. According to statistical analysis, since one of the student's score was not set in one standard deviation above and below the mean, she was not considered part of the study and the number of participants decreased to fifty eight.

Being homogeneous through the use of English proficiency test, the participants of the study including 58 EFL learners in two groups of control and experimental, took part in the pre-test, once tried in the pilot group. Before the pre-test administration in both control and experimental groups, the participants were informed that the test result would not be influentional in their final performance and those items which were not answered correctly would be given the negative mark. The subjects were informed about the time limitation- 30 minutes- and also about the fact that there was just one correct alternative for each test item. To be sure that all the students understood what they were expected to do, all the instructions were given in Persian. Regarding the reading comprehension test, the researcher organized each test passage over one of three rhetorical structures of "description", "comparison-contrast" and "cause-effect". Moreover, the questions which followed each passage asked about the kind of information each type of rhetorical structure should provide the reader with. In other words, the questions were designed to get at the kind of structure students learnt. Each of the passages contained between 120 to 140 words and 4 multiple choice questions. 
To assess the reading proficiency of the subjects in both control and experimental groups, the pre-post reading comprehension tests were used in this research before and after the treatment. The treatment was carried out during students' regular English classes, of each session, a quarter of time was devoted to reading comprehension, along with other three skills. The semester lasted forty five hours in ten weeks. Although the textbook- third volume of Interchange Third Edition (Richards, 2005) - was the same in both groups, the treatment was different and there was not any kind of consciousness raising on expository text structure among the subjects of control group; however, the time allocated to both groups was the same. After the administration of pre-test in both control and experimental groups, the treatment was run. In the control group the same passages were taught without teaching them the logical organization underlying each text. While the experimental group was going through the training sessions, the control group also received training with the same materials. They performed various tasks with the texts, for example, grammar exercises, sentence analysis, work with connectors, cohesion, and vocabulary work. They also focused on the content of the passages and used the texts as the basis for various reading and writing assignments. Subjects of the control group were taught in their reading class with the focus on vocabulary and grammar. There were some stages: First, the text was read by the teacher loudly and word by word as the learners followed. Then all the new vocabularies were written on the board and their meanings were clarified. Next, the grammatical rules associated with the passage were taught by the teacher. Learners worked on the text individually to achieve the comprehension. Along with the students' text book, several reading passages were accessible in both groups of control and experimental. Each passage contained a specific type of expository text structure. It is worth mentioning that in control group the subjects were not dealt with text structure awareness. In other word, the only thing the control group did not receive was the instruction on rhetorical organization and the strategy for using that information as a basis for reading and comprehending expository text.

Students could benefit from direct instruction in the five expository structures with which they encountered frequently. The teacher used strategies for teaching the structure in general and the five common expository text structures in particular. The framework was loosely based on the CORE model of Dymock (2005) - connection, organization, reflection and extension. Before teaching text structure, the teacher first taught the general concept of structure and the difference between structure and content. The teacher's first objective was to show students in the experimental group that the content of a passage consists of ideas, facts, and information, while the structure is a framework by which that content is organized. Teacher connected students to the content and the text structure. For instance, the teacher may clarify that a content about two different types of birds would be best organized with comparison/contrast rhetorical organization. In other words, connectedness is the link between what the reader knows (the content) and what is being learned (the text structure). In the experimental group, after reinforcing the difference between content and structure, the teacher used graphic organizers (visual displays of ideas and their organizations) to present expository paragraphs on different topics. A graphic organizer for a passage is a form of outline that specially represents its organization; a properly constructed graphic organizer presented along with the text, helped students visualize text structure. (McGee \& Richgels, 2005). Using graphic organizers shows how text is constructed and enables readers to make order out of the text. Showing how two texts with the same text structure have similar graphic organizer, the teacher emphasized the difference between content and structure. As a class activity, students were presented different reading passages of different structures with the same contents along with their graphic organizers adapted from Mayer and Freedle (1984). These texts made students of the experimental group more sensitive to text structures. The teacher introduced students to the ideas in the organizer (e.g. different types of birds) by the format which is the most appropriate to emphasize its structure (e.g. comparison-contrast), while the students discussed the key ideas in the organizer and especially the way they were related to each other. Therefore, the next strategy the teacher used in explicit teaching of expository text structure was diagramming the text which enabled students to see the structure and to understand and remember it better. Then the trainer could easily name the structure being used. Students were explained that expository texts have different organizational patterns which are called text structures. The teacher taught text structures one by one, as students needed time to master one structure before learning another. Some text structures seemed to be easier for students to grasp. The trainer tried to adjust the instruction of each specific rhetorical structure according to the structure of reading sections in students' text book. To identify structure, the teacher looked through the content materials in the text book for paragraphs which were organized by the five expository structures with appropriate clue words associated with the structure. Clue words help to identify structures by signaling particular relationships among ideas. Then, the teacher read each paragraph, as students followed reading in their own copy. Next, students analyzed the text, focusing on the specific structure. Students identified the sentences that represented the structural organization underlying them. They later circled the entire clue words. They took turns generating sentences associating with the structure. Reflect is where students explain or critique content, structures, and strategies (e.g., What kind of text did we analyze today? Why did we diagram the structure?). Then, an opportunity is provided to transferlearning to new topics. This extension gives a chance to reflect, as well as an opportunity for meaningful practice. The teacher encouraged them to use well-structured statements, that is, sentences that were based on the correct information from the paragraph and that included a clue word. Since the content material did not cover the five expository text structures well, the teacher also directed students' attention to additional paragraphs using that structure. As an additional strategy the teacher changed the writing sections in the students' text book in a way that the writing topic specified a kind of rhetorical structure though the topic content remained the same. Therefore, students applied 
their text structure knowledge in their writings as well. During all the stages, students were encouraged to work in groups and correct their peers.

At the end of the treatment, the same measurement was employed again as the post reading comprehension test for the both groups and the result of their comparison was used to determine whether the teaching of text structure among Iranian EFL students affects their ability to comprehend the main ideas of expository materials. Since two participants did not take part in the post- test, their data were eliminated from the study and they were not considered part of the study anymore; therefore, in the final analysis, the number of participants decreased to fifty six- each group was made up of twenty eight students. It is worth mentioning that, the subjects in the experimental group were not aware of receiving any special instruction until after completing the post test.

\section{DATA ANALYSIS}

The main purpose of this quasi-experimental research is to see the effect of teaching expository text structure on the reading comprehension of EFL learners. In order to describe different sets of scores, indices of central tendency, distribution and dispersion were used. Data obtained from the comparison of the two control and experimental groups were processed and analyzed using the 13th version of statistical package for the social sciences (spss). Since the main aim of this research was to determine the statistical significance of the difference between the means of two sets of scores, deriving from pre/post reading comprehension tests, t-test and correlation were used for the statistical analysis. A t-test was done after the proficiency test to determine whether the two groups were homogeneous; another t-test was run after the post test to reject the null hypothesis. Regarding the scoring procedure for the English proficiency test and teacher-made reading comprehension test in three groups of pilot, control and experimental, each correct response received a score of 1 , whereas each incorrect response received a negative mark. Moreover, each item which was not answered received nothing.

In this chapter, first the pilot group performance on preliminary English test and on teacher - made reading comprehension test will be presented. Then, the performance of sample under the study will be shown on the standardized test and developed reading comprehension test which is in the form of pre-post reading tests.

According to table 4.1, subjects in the pilot group were divided into two groups of students with high and low English proficiency level. (15 students in each group). The subjects performance was compared with each other in two groups. (The mean scores are 81.36 and 92.30). A t-test for equality of means was used and the t-value for a two-tailed test at .05 level of significance and 28 degrees of freedom is .00 . The performance of pilot group on the preliminary English test served as a criterion for validating the teacher-made reading comprehension test.

TABLE 4.1

DESCRIPTIVE STATISTICS OF PILOT GROUP PERFORMANCE ON THE PET

\begin{tabular}{|l|l|l|l|l|}
\hline group & $\mathrm{N}$ & Mean & Std. Deviation & Std. Error Mean \\
\hline low & 15 & 81.36 & 4.49 & 1.16 \\
\hline high & 15 & 92.30 & 3.77 & .97 \\
\hline
\end{tabular}

According to table 4.2, the mean scores in two groups of students with high and low language proficiency, were compared. (1.06 and 7.13). The comparison shows a noticeable difference between the groups performance. It implies that subjects with high language ability out performed on the developed reading comprehension test than those with low language proficiency.

TABLE 4.2

DESCRIPTIVE STATISTICS OF PILOT GROUP PERFORMANCE ON DEVELOPED READING TEST

\begin{tabular}{|l|l|l|l|l|}
\hline group & $\mathrm{N}$ & Mean & Std. Deviation & Std. Error Mean \\
\hline low & 15 & 1.06 & .70 & .18 \\
\hline high & 15 & 7.13 & 2.47 & .63 \\
\hline
\end{tabular}

The calculated t-value (.00) is more than the critical value for a two-tailed test at .05 level of significance and 28 degrees of freedom; therefore, the use of t-test revealed that in the pilot group the difference between the performances of students with high and low English proficiency level on the reading comprehension test, was significant.

The Pearson correlation coefficient between scores of proficiency English test and teacher made reading comprehension test, both administered among the subjects of pilot group, was conducted. The correlation was high and positive at .o1 level of significance (0.89). It implies that, the students' English proficiency level highly affected their test performance. In other words, more professional English learners out performed on the reading test and vice versa.

Regarding the samples' last term scores, an initial judgment towards the homogeneity of the sample was formed. The sample under the study consisted of 56 EFL students, of those 26 subjects assigned to control group and 26 subjects assigned to experimental group. The subjects' last term scores were statistically described in the table 4.3. 
TABLE 4.3

DESCRIPTIVE STATISTICS OF SUBJECTS' LAST TERM SCORES

\begin{tabular}{|l|l|l|l|l|}
\hline group & $\mathrm{N}$ & Mean & Std. Deviation & Std. Error Mean \\
\hline control & 28 & 84.26 & 4.25 & .80 \\
\hline experimental & 28 & 85.19 & 4.86 & .91 \\
\hline
\end{tabular}

According to table 4.3, the mean scores - the main indicators - are quite close to each other in two groups of control and experimental. (84.2 and 85.1). A t-test was run to determine whether the score difference between these two groups was significant. Since the t-value did not exceed the t-critical value (.477), the students were homogeneous with respect to their last term scores.

TABLE 4.4

DESCRIPTIVE STATISTICS OF SUBJECTS' PERFORMANCE ON PET

\begin{tabular}{|l|l|l|l|l|}
\hline group & $\mathrm{N}$ & Mean & Std. Deviation & Std. Error Mean \\
\hline control & 28 & 20.51 & 5.85 & 1.12 \\
\hline experimental & 28 & 21.39 & 4.84 & .91 \\
\hline
\end{tabular}

With the use of indicators such as mean, standard deviation and standard error of mean, the performance of students on the English proficiency test in two groups of control and experimental, was statistically described in the table 4.4.

Since the t-value was less than t-critical value (.123), the difference between subjects' performance on the prereading comprehension test in both groups of control and experimental was not significant. Mean, standard deviation and standard error of mean in both groups were compared. They also confirmed the homogeneity of subjects' performance. It implies that in both groups the participants almost reacted similarly to the independent variable (expository text structure).

TABLE 4.5

DESCRIPTIVE STATISTICS OF SUBJECTS' PERFORMANCE ON PRE-TEST

\begin{tabular}{|l|l|l|l|l|}
\hline group & $\mathrm{N}$ & Mean & Std. Deviation & Std. Error Mean \\
\hline control & 28 & -1.41 & 1.21 & .22 \\
Experimental & 28 & -.87 & 1.37 & .25 \\
\hline
\end{tabular}

Table 4.6 shows the amount of mean, standard deviation and standard error of mean in both groups of control and experimental. Through the use of descriptive statistics there is about 6.5 degrees of progress in the mean scores of two groups - an indicator of central tendency index.

TABLE 4.6

DESCRIPTIVE STATISTICS OF SUBJECTS' PERFORMANCE ON POST-TEST

\begin{tabular}{|l|l|l|l|l|}
\hline group & $\mathrm{N}$ & Mean & Std. Deviation & Std. Error Mean \\
\hline control & 28 & -.49 & 1.26 & .23 \\
\hline experimental & 28 & 6.17 & 2.59 & .48 \\
\hline
\end{tabular}

The considerable difference in the performance of subjects on post-test in both groups of control and experimental showed the amount of impact that the independent variable applied.

Descriptive statistics implied a noticeable difference between performances of students in control and experimental groups. The t-value was less than t-critical value (.00); therefore, the difference between two groups' performance after the treatment was significant.

Based on statistics, it is quite obvious that how greatly experimental students improved in their performance on the post reading test. The majority of students who responded correctly are of experimental group; therefore, the null hypothesis would be strongly rejected.

TABLE 4.7

DESCRIPTIVE STATISTICS OF DIFFERENCE BETWEEN GROUPS' PERFORMANCE

\begin{tabular}{|l|l|l|l|l|}
\hline group & $\mathrm{N}$ & Mean & Std. Deviation & Std. Error Mean \\
\hline control & 28 & .92 & 1.18 & .22 \\
\hline experimental & 28 & 7.04 & 2.12 & .40 \\
\hline
\end{tabular}

The amount of difference between the performance of two groups of control and experimental is statistically described in the table 4.7. The mean score shows 7 degrees of difference between two groups' performances. A t-test was run to indicate that the difference is significant (.00) 
TABLE 4.8

DESCRIPTIVE STATISTICS OF CONTROL/ EXPERIMENTAL GROUP PERFORMANCE

\begin{tabular}{|l|l|l|l|l|}
\hline Group & Test & Mean & Std. Deviation & Std. Error Mean \\
\hline \multirow{2}{*}{ Control Group } & Pre-test & -1.41 & 1.21 & .22 \\
\cline { 2 - 5 } & Post-test & -.49 & 1.26 & .23 \\
\hline \multirow{2}{*}{ Experimental Group } & Pre-test & -.87 & 1.37 & .25 \\
\cline { 2 - 5 } & Post-test & 6.17 & 2.59 & .48 \\
\hline
\end{tabular}

Descriptive statistics of control and experimental groups' performance on both pre and post reading comprehension tests was demonstrated in the table 4.8. Performance of students in control group in both tests along with performance of students in experimental group in pre - test are highly close together. The experimental students' performance in the post- test is completely different. (Mean $=6.17$, Std. Deviation $=2.59$, Std. Error Mean $=.48$ ).

The correlation coefficient between pre and post scores of control group was high and positive. (0.54). It implied that the control group performance on the post test did not changed significantly. It could be another confirmation for the stability of control group performance from pre to post reading test. As a result of a t-test, since the $t$-value was less than t-critical value (.00); therefore, the difference between the performance of students in pre-test and post-test in experimental group was significant.

Comparing with the performance of subjects of experimental group in the pre-test, the amount of progress in their performance on the post-test was clarified with the use of graph 4.1. Although there is score progress from pre to post reading comprehension test in control group, it is not as considerable as that of experimental group.

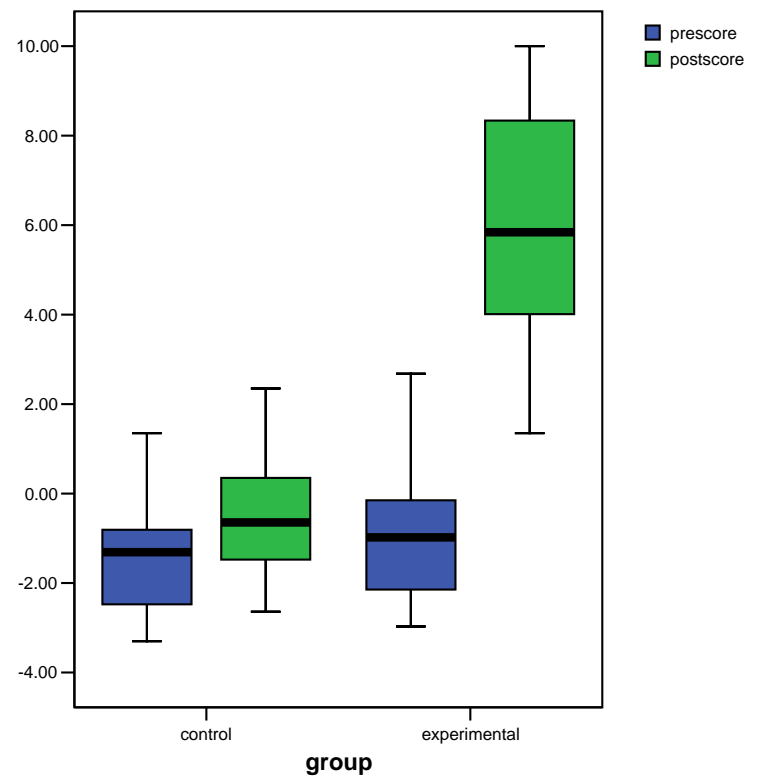

Graph 4.1 The overall performance of control and experimental groups

The performance on pre, post reading comprehension tests in two groups of control and experimental was illustrated through the use of graph 4.1. It clearly shows a great amount of progress in the experimental group's post scores. The bold lines in the middle of squares indicate the median scores in each group.

\section{CONCLUSION}

In response to the research question investigated if teaching of expository text structure affects Iranian EFL students' reading comprehension of expository text, the findings of this study will be discussed.

In the interactive model of reading comprehension, reading is viewed as the reconstruction of meaning from the interaction between reader and the text. In this view text structure knowledge plays an important role in comprehension and recall. A number of research studies with native and non-native speakers of English that investigated the role of rhetorical structure in text comprehension have provided support that direct instruction of text structure enhances the reader's comprehension, recall, and retention of text (Armbruster, Anderson \& Ostertag, 1987; Carrell, 1984a, 1984b, 1985 , 1992). In other words, students who use the structure strategy will be able to comprehend the gist of expository text better.

The analysis results reported in the present study provide support to the findings of the previous studies. It was found that there were significant differences in the performance of subjects who were exposed to text structure training comparing to the performance of those who were not. Then the use of text structure as a reading strategy in text processing, may have provided facilitative effects for Iranian EFL students to comprehend expository prose. 
A reasonable explanation for these findings is that subjects who were aware of text structure and used it as their strategic approach to text processing may have gone through the process of discourse comprehension. (Meyer, 1975a; Meyer, Brandt \& Bluth, 1980; Kintsch \& van Dijk, 1978). That is, the readers tried to find a sort of cohesion among sentences of a text while these relations activated the relevant background knowledge in the reader's mind. After that the subjects made a proper match between the text new information and the active schema. Then, the meaning was reconstructed and the subjects could remember what they read efficiently. Subjects who employed the structure strategy had a significantly higher performance in text comprehension. This finding can be as an additional support that using text structure guides the subjects to better comprehend and learn from the text. The subjects in control group who have not received any training in text organization, did not have a systematic plan to guide their comprehension. Therefore, in the multiple choice question answering, these subjects remembered fewer main ideas than those who were taught the structure strategy. They simply did what they could remember from the text.

The goal of educators and teachers is to enhance students' reading achievement. The goal of students is to comprehend what they read. Cziko (1980). The students' failure in reading may affect their educational process. The improvement in reading should be achieved with the help of teacher or students themselves; otherwise, the students' reading achievements would be low. One problem of ESL/EFL students is they are not able to employ reading strategies suitable to what they read. Employing appropriate reading strategies helps students improve in reading comprehension (Carrell, 1992). Lee (1986), examined why EFL learners did not succeed in learning English, and found that the students failed to apply appropriate strategies to reading. To solve these problems, reading strategies should be explicitly taught to EFL students (Carrell, 1985). Applying knowledge of text structures such as description, sequence, problem-solution, cause-effect, or compare-contrast to comprehend and recall the expository text was one of the effective reading comprehension strategies (Miller \& George, 1992; Carrell, 1984). Thus, reading teachers have to look for effective reading strategies for expository passages. Therefore, it is necessary to conduct a study to investigate the effects of direct instruction of text structures on EFL students' reading comprehension.

With the pretest-posttest control-experimental design, the research focus was on the performance of a treatment group compared with a control group. Data were collected from 59 students who took the test in their EFL class. The study described the test takers' performance on the three reading comprehension tests quantitatively through statistical analyses. The total number of 59 students who took the test in the classroom was reduced to 56 after a selection of valid cases and deletion of outliers. The remaining subjects made up a highly homogeneous group, of which 28 subjects assigned to control and 28 students assigned to experimental group. The experimental group was taught reading through discussion of text structures, while the control group was taught reading without any consciousness raising over text structures. The performance of control and treatment groups in the three reading comprehension tests was analyzed. By demonstrating that the treatment group significantly outperformed the control group from pretest to posttest, the study results showed statistically the effectiveness of direct training of expository text structure awareness. Therefore the research question: "Does explicit teaching of different kinds of expository text structure, affect EFL students' reading comprehension?" has been answered positively and the null hypotheses: "EFL students at intermediate English proficiency level do not perform better on their reading comprehension test after being taught in text structure", has been rejected. This statement implies that the performance of EFL learners on the reading skill is highly affected by the direct training of expository rhetorical structures. The results from t-testrevealed that a reader's rhetorical structure knowledge and his ability to use the same structure as the original text, affect his/her comprehension. The better the reader recognizes and uses the original structure of the text, the better his/her comprehension. Experimental students in this study appeared to be able to use text structure knowledge to enhance comprehension. The results of this research strongly imply that text structure should be explicitly taught as part of an instructional program in ESL/EFL reading.

The findings of this study can lead to the pedagogical implications for the teaching of reading English to ESL/EFL students. Since there are students who are unaware of text structure or who may have knowledge of text structure but they are not able to use it as a strategy in reading; therefore, the knowledge of expository text structures should be instructed to second/foreign language learners and must be included in ESL/EFL reading curriculum. Although teachers do their best in teaching the grammar and vocabulary of the English language, they often can see their students with adequate knowledge of the vocabularies and structures fail to comprehend what they have read. Their difficulty in reading comprehension may result from their lack of necessary reading strategies or skills to help them learn from text (Richgels, McGee, Lomax \& Sheard, 1987). To solve this problem, the teacher should provide students with explicit instruction and training in the use of expository text structure. They should incorporate text structure and signaling devices into the textbooks and instructional materials. They should provide the opportunity for ESL/EFL students to be exposed to various reading passages organized with different types of text structure. Moreover the writing teachers can also apply the findings of this study in their composition classes. Employing the knowledge of text structure is as essential in writing as in reading. To form a coherent writing, students can use text structure as a guide for revising what they have written.

\section{REFERENCES}

[1] Abdollahzadeh, E. (2006). Explicit/implicit signals, rhetorical structure and reading comprehension. Unpublished doctoral dissertation. Tehran: Tehran University. 
[2] Aebersold, J. A., \& Field, M. L. (Eds.). (1997). From reader to reading teacher issues and strategies for second language classrooms (pp. 21-34). Cambridge: Cambridge University Press.

[3] Anderson, R C., Reynolds, R E., Schallert, D. L., \& Goetz, E.T. (1977). Frameworks for comprehending discourse. American Educational Research Journal, 14,367-381

[4] Armbruster, B. B., Anderson, T. H., \& Ostertag, J. (1987). Does text structure/summarization instruction facilitate learning from expository text? Reading Research Quarterly, 12,331-346.

[5] Carrell, P. L. (1984a). The effects of rhetorical organization on ESL readers. TESOL Quarterly, 18,441-469.

[6] Carrell, P. L. (1984b). Evidence of a formal schema in second language comprehension. Language Learning, 34, 87-112.

[7] Carrell, P. L. (1985). Facilitating ESL reading by teaching text structure. TESOL Quarterly, 19, 727-752.

[8] Carrell, P. L. (1988a). Introduction: Interactive approaches to second language reading. In P. L. Carrell, J. Devine, \& D. E. Eskey (Eds.), Interactive approaches to second language reading (pp. 1-7). Cambridge, NY: Cambridge University Press.

[9] Carrell, P. L. (1988b). Some causes of text-boundedness and schema interference in ESL reading. In P. L. Carrell, J. Devine \& D. E. Eskey (Eds.), Interactive approaches to second language reading (pp. 101-113). Cambridge, NY: Cambridge University Press.

[10] Carrell, P. L. (1992). Awareness of text structure: Effects on recall. Language Learning, 42, 1, 1-20.

[11] Cziko, G. A. (1980). Language competence and reading strategies: A comparison of first-and second-language oral reading errors. Language Learning, 30, 101-116.

[12] Dewalt, M., Rhyne-Winkler, M. c., \& Rubel, S. (1993). Effects of instructional method on reading comprehension. Reading Improvement, 30, 93-100.

[13] Dymock, S.(2005).Teaching expository text structure awareness. The Reading Teacher, 59, 2, 177-82.

[14] Grabe, W. (1991). Current developments in second language reading research. TESOL Quarterly, 25, 375-406.

[15] Hooshmand, D. (1984). The Organization of Prose and its Effects on Reading English as a Foreign Language. Unpublished doctoral dissertation. University of Illinois at Urbana-Champaign.

[16] Kendeou,P \& Broek P.(2007). The effects of prior knowledge and text structure on comprehension processes during reading of scientific texts. Memory \& Cognition. 35, 7, 1567-1577.

[17] Kintsch, W., \& van Dijk, T. A. (1978). Toward a model of text comprehension and production. Psychological Review, 85, 363394.

[18] Lee, J. (1986). Background knowledge and L2 reading. Modern Language Journal, 70, 350-354.

[19] Meyer, B. J. F. (1975a). Identification of the structure of prose and its implications for the study of reading and memory. Journal of Reading Behavior, 7, 747.

[20] Meyer, B. J. F. (1982). Reading research and the composition teacher: The importance of plans. College Composition and Communication, 33, 37-49.

[21] Meyer, B. J.F., Brandt, D. M., \& Bluth, G. J. (1980). Use of top-level structure in text Key for reading comprehension of ninthgrade students. Reading Research Quarterly, 16, 72-103.

[22] Meyer, B. J. F., \& Freedle, R. O. (1984). Effects of discourse type on recall. American Educational Research Journal, 21, 121143.

[23] Miller, K. K., \& George, J. E. (1992). Expository passage organizer: Models for reading and writing. Journal of Reading, 35, 372-377.

[24] Newman, L. M. (2007). The effects of explicit instruction of expository text structure incorporating graphic organizers on the comprehension of third-grade students. Unpublished doctoral dissertation. University of Maryland.

[25] Piyanukool, S. (2001). Effects of teaching reading through discussion of text structures. Unpublished doctoral dissertation. Texas: University of North Texas.

[26] Richards, J.C., Hull, J. \& Proctor, S. (2005). Interchange Third Edition: Student's Book. In Bohlke, D., Chen, J., \& Hara, Y. (Eds). Cambridge, NY: Cambridge University Press.

[27] Richards, J.C., \& Schmidt, R. (2002). Dictionary of language teaching and applied linguistics. Longman. Pearson Education.

[28] Richgels, D. J., McGee, L. M., Lomax, R. G., \& Sheard, C. (1987). Awareness of four text structures: Effects on recall of expository text. Reading Research Quarterly, 12, 177-196.

[29] Slater, W. H. (1985). Teaching expository text structure using structural organizers. Journal of Reading, 28, $712-718$.

[30] Spearritt, D. (1982). Identification of subs kills of reading comprehension by maximum likelihood factor and analysis. Reading Research Quarterly, 8, 92-111.

[31] Talbot, D.C.(2004). Metacognitive strategy training for reading: Developing second language learners' awareness of expository text patterns. Unpublished doctoral dissertation. University of Hong Kong.

[32] Taylor, B. M. (1982). Text structure and children's comprehension and memory for expository material. Journal of Educational Psychology, 74, 323-340.

[33] Taylor, B. M., \& Samuels, S. J. (1983). Children's use of text structure in the recall of expository material. American Educational Research Journal, 20, 517528.

Azadeh Elmianvari was born in Hamedan, Iran in 1982. She is currently the student of Advanced Master in Linguistics (Linguistics in a Comparative Perspective) at Gent University, Belgium. She has completed her Master degree in Teaching English as a Foreign Language (TEFL), at Allame Tabataba'i University in Tehran, Iran in 2009. Her BA is in English Literature from Alzahra University, Tehran, Iran in 2005.

From March, 2009 to June, 2011 she was a lecturer at three universities in Hamedan, Iran: BuAliSina University, Payame Noor University and Hamadan University of Technology.

Miss Elmianvari is planning to do her $\mathrm{PhD}$ at KULeuven, Belgium in the coming academic year in Applied Linguistics. Her main field of interest is the incorporation of technology in second/foreign language teaching. 
Reza Kheirabadi was born in Tehran, Iran in 1979. He has just completed his PhD in General Linguistics at Tarbiat Modares University (Tehran, Iran) in 2012, and received his M.A. from the same university in 2006.He is now passing a 6 months scholarship in Gent, Belgium with News Text and Talk (NT\&T) Research Group.

$\mathrm{He}$ is currently working for Organization for Educational Research and Planning (OERP) which is the official body to prepare textbook materials and curriculum planning in Iran. He also has the experience of working for leading Iranian newspapers and news agencies as journalists and translator.

His main research interests are News production process, Language of News, Critical Discourse Analysis of news and ethnographic study of journalistic activities in Iran. His MA thesis was also about linguistic study of news values in press of Iran.

Dr. .Kheirabadi is a research assistant of NT\&T and a member of Public Relations Expert Association of Iran. 